\title{
Where Mendeleev was wrong: predicted elements that have never been found
}

\author{
Gábor Lente ${ }^{1} \mathbb{0}$
}

Received: 28 April 2019 / Accepted: 26 July 2019 / Published online: 26 August 2019

(c) The Author(s) 2019

\begin{abstract}
This contribution gives a detailed account of the element predictions Dmitri Ivanovich Mendeleev made after setting up the periodic table of the elements in 1869 , with a special focus on those that turned out to be unsuccessful. It is argued that most of these instances are connected to a general inability to place the rare earth metals correctly into the system. Furthermore, details of conceiving the ideas for two lighter-than-hydrogen elements, newtonium and coronium, are discussed. An attempt is made to retro-engineer the sequence of thought that led Mendeleev to extrapolate atomic masses for these elements.
\end{abstract}

Keywords Periodic table $\cdot$ Mendeleev $\cdot$ Rare earth metals $\cdot$ Ether $\cdot$ Element discovery

\section{Introduction}

2019 is the international year of the periodic table of chemical elements, which provides a good occasion to popularize chemistry through recalling both the scientific principles and the human stories behind the periodic table. Needless to say, the historical aspects are centered mostly on Dmitri Ivanovich Mendeleev (1834-1907), who is remembered both as the uncontested champion of discovering the natural system of chemical elements and the tireless communicator who made the ideas known to the widest possible audience [1-12].

Taking into account the scientific information known in the middle of the 19th century, it is probably fair to say that chemistry was ready for the discovery of the periodic table: there were numerous independent attempts at organizing the elements known at that time, atomic masses were mostly (correctly) determined, and the introduction of the spectroscopic method in $1860[13,14]$ reduced the incidence of false element identifications (although did not eliminate them entirely), which was a major problem hindering any element-systematization work in the first half of the 19th century.

Gábor Lente

lenteg@gamma.ttk.pte.hu

1 Department of General and Physical Chemistry, University of Pécs, Pécs, Hungary
One of the major reasons why Mendeleev is given most of the credit for developing the periodic table is that he made regular attempts to extract the scientific logic of the system and make verifiable (or falsifiable) predictions based on it $[1,4,6,10,12]$. Some of the early predictions were verified within 20 years of the first publication. This bit of science history is often recalled in textbooks; even Wikipedia has a page on the significance of these success stories [15]. Needless to say, being able to predict unknown phenomena or the existence of unknown substances is one of the strongest arguments in favor of the validity of a scientific theory. Yet the author of this article would like to focus on Mendeleev's less successful lines of arguments $[1,10,16]$ in the hope that they will help the reader to understand the logic behind the work of the great Russian scientist, and also to give some insights into some general questions of scientific thinking.

\section{Successful early predictions}

The exact date on which Mendeleev was enlightened with the thought of the periodic law [1] is February 17, 1869 on his local timekeeping, but March 1 in most of Europe because of a difference between the Julian and Gregorian calendars. Mendeleev was working on a book entitled “Основы химии" (Osnovy Khimii, Foundations of chemistry) [17]. However, his sudden insight must have given him a strong feeling of major achievement, which is indicated by the fact that he published the periodic table in at least three 
different articles (once in Russian, twice in German) in the year of 1869 [18-20]. Table 1 shows one of the primordial forms [19]. Today, it is known as the short form of the periodic table $[1,21]$.

The basic idea of the system is that the elements should be arranged in the order of their atomic masses, which were determined by diligent but probably also quite boring scientific work in the preceding half century. With this arrangement, the chemical (and also some of the physical) properties return periodically so that elements with similar characteristics occupy a single column. There was only one point where this logic seemed to fail: iodine, which is certainly the chemical analog of bromine and not selenium, had a lower atomic mass than tellurium, whose resemblance to selenium was beyond any doubt. Incidentally, tellurium was already displayed before iodine by Julius Lothar Meyer (1830-1895) in his system of elements in 1864 [22]. Mendeleev did not accept the experimentally determined atomic mass for tellurium, but assumed a relatively small error and included 125, as shown in Table 1. However, this did not solve the problem for a long time; the issue of the anomalous atomic mass of tellurium kept returning in his later years as well. His most inventive solution was that tellurium has a larger than expected atomic mass because it was not prepared in an entirely pure form but contained some of its heavier analog dvi-tellurium [23], which was the name given to the unknown element that should appear after bismuth in the periodic table. The prefix "dvi" in this name comes from the Sanskrit word for "two" and was used by Mendeleev for the second higher element analog. The prefixes "eka" ("one" in Sanskrit) and "tri" (three in Sanskrit) were used in a similar manner.

Before judging this practice ("bending" reality to match theory) too harshly, one should also consider the fact that
Mendeleev changed the accepted atomic masses of some other elements as well and turned out to be correct [1]. For example, beryllium was commonly assigned an atomic mass of 14 at that time, which is the same as that of nitrogen. Based on property similarity, Mendeleev proposed that the valence of beryllium was erroneously assigned and that its actual atomic mass should be the non-integer value of 9.4, which placed it right above magnesium. Uranium was another success story: its accepted atomic mass was 120 , which would have placed it between tin and antimony, where there was certainly no column of similar elements. So again, revising the valence led to an atomic mass of 240 , which was larger than any other known atomic masses at that time, but at least placed uranium into a position that could be reasonably described as the one below tungsten, which was fully supported by chemical intuition.

Quite a number of elements were discovered in the decades before 1869 , and no scientist could have any doubt about one fundamental thing: more elements were going to be found. Competent handling of this "missing knowledge" is probably the most important reason why Mendeleev became the dominant scientist in this field. Even in the early forms of the table, he left empty positions for elements that were undiscovered at that time. In Table 1, there are 29 such empty spaces marked with a "-" sign with the clear intention that an element is expected in that place (Lothar Meyer did the same in his earlier work [22]). Four of these positions come with extra information: a predicted atomic mass. These are " $-=44 ", "-=68 ", "-=72 ", "-=100 "$. In later years, Mendeleev had the habit of making further predictions and named the missing elements after the element above it in the periodic table using the prefix "eka", as mentioned before, which is a bit weird given the fact that in Mendeleev's favorite short form of the periodic table, all

Table 1 Mendeleev's periodic table in 1869 [20]

\begin{tabular}{|c|c|c|c|c|c|c|c|c|}
\hline String & $\begin{array}{l}\text { Group I } \\
- \\
\mathrm{R}_{2} \mathrm{O}\end{array}$ & $\begin{array}{l}\text { Group II } \\
- \\
\text { RO }\end{array}$ & $\begin{array}{l}\text { Group III } \\
- \\
\mathrm{R}_{2} \mathrm{O}_{3}\end{array}$ & $\begin{array}{l}\text { Group IV } \\
\mathrm{RH}_{4} \\
\mathrm{RO}_{2}\end{array}$ & $\begin{array}{l}\text { Group V } \\
\mathrm{RH}_{3} \\
\mathrm{R}_{2} \mathrm{O}_{5}\end{array}$ & $\begin{array}{l}\text { Group VI } \\
\mathrm{RH}_{2} \\
\mathrm{RO}_{3}\end{array}$ & $\begin{array}{l}\text { Group VII } \\
\mathrm{RH} \\
\mathrm{R}_{2} \mathrm{O}_{7}\end{array}$ & $\begin{array}{l}\text { Group VIII } \\
- \\
\mathrm{RO}_{4}\end{array}$ \\
\hline 1 & $\mathrm{H}=1$ & & & & & & & \\
\hline 2 & $\mathrm{Li}=7$ & $\mathrm{Be}=9.4$ & $\mathrm{~B}=11$ & $\mathrm{C}=12$ & $\mathrm{~N}=14$ & $\mathrm{O}=16$ & $\mathrm{~F}=19$ & \\
\hline 3 & $\mathrm{Na}=23$ & $\mathrm{Mg}=24$ & $\mathrm{Al}=27.3$ & $\mathrm{Si}=28$ & $\mathrm{P}=31$ & $\mathrm{~S}=32$ & $\mathrm{Cl}=35.5$ & \\
\hline 4 & $K=39$ & $\mathrm{Ca}=40$ & $-=44$ & $\mathrm{Ti}=48$ & $V=51$ & $\mathrm{Cr}=52$ & $\mathrm{Mn}=55$ & $\mathrm{Fe}=56, \mathrm{Co}=59, \mathrm{Ni}=59, \mathrm{Cu}=63$ \\
\hline 5 & $(\mathrm{Cu}=63)$ & $\mathrm{Zn}=65$ & $-=68$ & $-=72$ & As $=75$ & $\mathrm{Se}=78$ & $\mathrm{Br}=80$ & \\
\hline 6 & $\mathrm{Rb}=85$ & $\mathrm{Sr}=87$ & $? \mathrm{Yt}=88$ & $\mathrm{Zr}=90$ & $\mathrm{Nb}=94$ & $\mathrm{Mo}=96$ & $-=100$ & $\mathrm{Ru}=104, \mathrm{Rh}=104, \mathrm{Pd}=106, \mathrm{Ag}=108$ \\
\hline 7 & $(\mathrm{Ag}=108)$ & $\mathrm{Cd}=112$ & $\mathrm{In}=113$ & $\mathrm{Sn}=118$ & $\mathrm{Sb}=122$ & $\mathrm{Te}=125$ & $\mathrm{~J}=127$ & \\
\hline 8 & $\mathrm{Cs}=133$ & $\mathrm{Ba}=137$ & $? \mathrm{Di}=138$ & $? \mathrm{Ce}=140$ & - & - & - & ---- \\
\hline 9 & $(-)$ & - & - & - & - & - & - & \\
\hline 10 & & & $? \mathrm{Er}=178$ & $? \mathrm{La}=180$ & $\mathrm{Ta}=182$ & $\mathrm{~W}=184$ & - & Os $=195, \mathrm{Ir}=197, \mathrm{Pt}=198, \mathrm{Au}=199$ \\
\hline 11 & $(\mathrm{Au}=199)$ & $\mathrm{Hg}=200$ & $\mathrm{Tl}=204$ & $\mathrm{~Pb}=207$ & $\mathrm{Bi}=208$ & - & - & \\
\hline 12 & - & - & - & $\mathrm{Th}=231$ & - & $\mathrm{U}=240$ & - & ---- \\
\hline
\end{tabular}


the eka-names come from the element two rows above the missing one. This might indicate that Mendeleev must have thought of two lines as one unit; this is further emphasized by the alternating alignments of the symbols in odd and even rows. Therefore, "- $=44$ " was called eka-boron, " $-=68$ " is eka-aluminum, and " $-=72$ " is eka-silicon, whereas “- =100" was referred to as eka-manganese. Using various interpolation methods, Mendeleev even made predictions about the physical and chemical properties of the elements. Experimental discoveries in the next two decades confirmed some of Mendeleev's most detailed predictions. The French chemist Emile Lecoq De Boisbaudran (1838-1912) discovered gallium in 1875 [24], which was soon understood to be identical to the predicted eka-aluminum. Lars Fredrik Nilson (1840-1899) from Sweden found scandium in 1879 [25], which matched the predictions for eka-boron. German scientist Clemens Winkler also (1838-1904) identified a new element in 1886 and, following the example of the previous discoverers in a flurry of patriotic feeling, named it germanium [26]. Others recognized that germanium is actually the same as eka-silicon. Finally, eka-manganese had to be prepared artificially in a less patriotic age, hence the name technetium, this achievement was reached in 1937 by Carlo Perrier (1886-1948) and Emilio Segrè (1905-1989) $[27,28]$. The striking accuracy of Mendeleev's predictions is often discussed today in introductory textbooks, and certainly contributed both to the general acceptance of the periodic law and Mendeleev's personal reputation as well.

\section{Discrepancies in the early periodic table}

It is even more instructive to think about the cases where later discoveries did not support Mendeleev's predictions or some other preferences he expressed in his publications. First and foremost, the 63 elements in the primordial periodic table shown in Table 1 do not include terbium (Tb), whose discovery - along with erbium (Er), which is present in Table 1-today is credited to the work of Carl Gustav Mosander (1797-1858) in 1843 [29]. Even more interesting is the fact that Table 1 includes fluorine, for which the discovery is typically dated to 1886 and credited to Henri Moissan (1852-1907) [30]. This contradiction can be explained by the fact that fluorine was recognized to be an element and named long before it was successfully isolated in its elemental from. The elements erbium and lanthanum (La) are included with atomic masses that are nowhere near their current values. Finally, there is a symbol Di in row 8 .

These mistakes and apparent contradictions are almost natural consequences of the limitations of scientific knowledge at that time. The original definition of an element was "a substance that cannot be decomposed to anything simpler". When only chemical methods of analysis were available, there was a lot of room for error in identifying elements. The history of science lists many more mistakes than the actual number of chemical elements. One of the significant divides in the history of chemistry is the introduction of atomic spectroscopy in Heidelberg, which was published in 1860 by chemist Robert Wilhelm Eberhard Bunsen (1811-1899) and physicist Gustav Robert Kirchoff (1824-1887) [13, 14]. This method is based on creating atoms (usually in the plasma of a chemical flame) and then analyzing the light they emit. Spectral lines, i.e. components with very strictly monochromatic wavelengths, appear in this light, and the lines are understood to indicate the presence of an element. The experiment is reasonably simple and can be carried out with most samples. After the introduction of spectroscopy, mixtures of already known elements were very unlikely to be mistaken for a new element. It is by no means accidental that Mendeleev was a guest researcher in Heidelberg in 1860; he was interested in this method and this interest is probably the major reason that no element identification error appears in Table 1 except the case of Di, which stands for the supposed element didymium.

This mistake can be traced back to Mosander, whose name was already mentioned as the discoverer of terbium and erbium (and, by the way, also lanthanum). It seems that Mendeleev did not trust the existence if terbium, but believed in didymium, which was first described in 1842 following an analysis of the trace elements in the mineral cerite [31]. The name came from the Greek word $\delta 1 \delta v \mu o$ (didymo), which means twin. However, the "discovery" was the source of further discrepancies: cerium, lanthanum and didymium were still only $95 \%$ of the rare earth content of cerite. The first experiments to determine the atomic mass of didymium gave quite controversial results between 73 and 95, which were not even in the correct range (138 is shown in Table 1). After the discovery of spectroscopy, it was recognized that didymium samples prepared from different mineral sources showed very different spectra, so Di could not be a single element. Finally, Carl Auer von Welsbach (1858-1929) managed to separate didymium into two elements [32]. The first was called green didymium, praseo-didymium in Greek, the second was called new didymium, neo-didymium. These became somewhat shortened to give the modern element names praseodymium and neodymium. They are not only twins in their names, they are immediate neighbors in the periodic system.

\section{A long battle with the rare earths}

It is quite fitting to discuss the rare earth metals in an article about Mendeleev's erroneous predictions, as the inability to find a good placement for them was probably the single most important source of mis-predictions [2, 8]. Mendeleev 


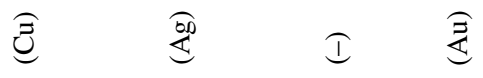

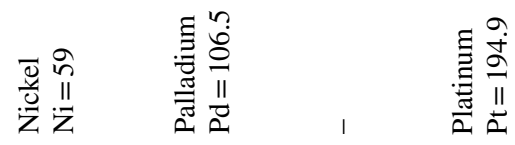

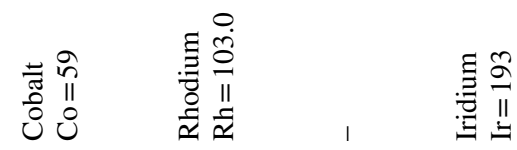

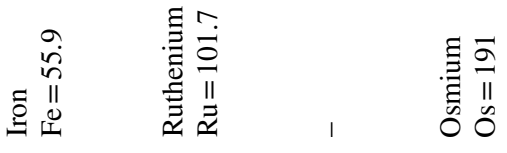

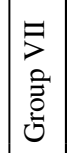

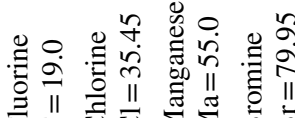

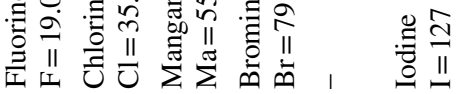

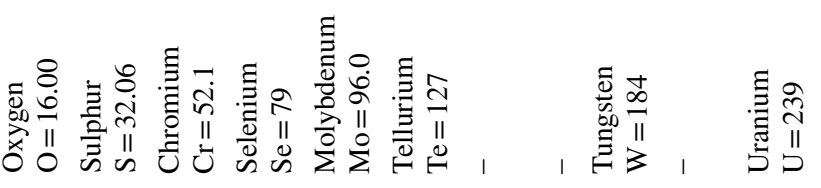

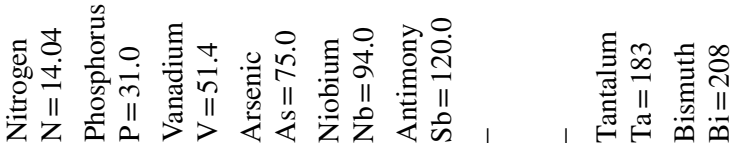

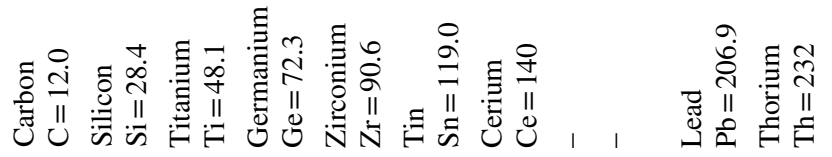

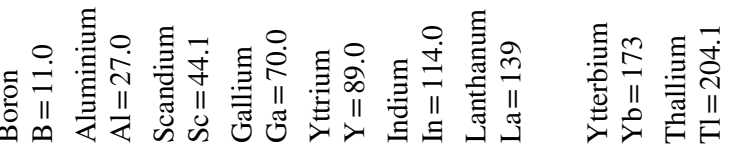

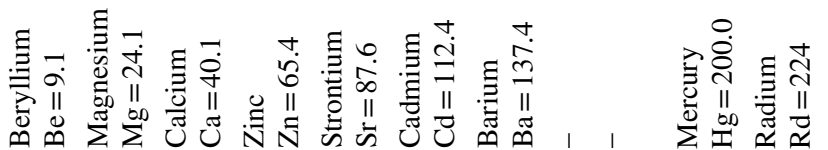

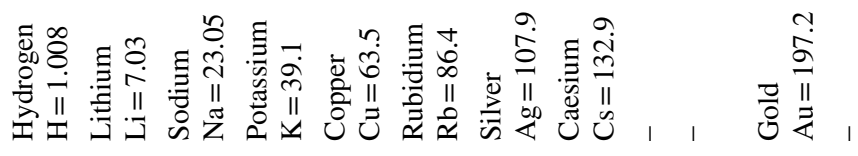

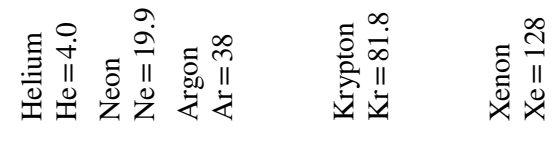


published his last update on the periodic table in 1904 (Table 2) [33]. At this time, 12 of the 14 metals shown in the first row of the f block today were already known (lutetium was discovered in 1907, unstable promethium only in 1945). In this table, it is interesting to note that Mendeleev correctly dropped $\mathrm{Di}$, but did not introduce $\mathrm{Nd}$ and Dy instead. Seventy-one elements are listed in this table, despite the fact that 84 were already known in 1904.

From this table, the place for the missing element technetium is easy to see, as is the place for astatine. A less obvious, but still excellent insight is the prediction of a missing element between uranium and thorium. Although polonium (similarly to radium) was already known and Mendeleev even predicted it with the name dvi-tellurium [23], this was not placed into the system. This may have to do with the disappointment of the Russian scientist with the still unresolved question of the atomic mass of tellurium, as the known properties of polonium certainly excluded the possibility of its presence as a constant impurity in tellurium samples. It can also be noted that lanthanum and ytterbium are shown with correct atomic masses in Table 2. Yet general confusion about the rare earth elements is still clear in it. Thyssen and Koen Binnemans wrote an excellent essay on the problematic accommodation of the rare-earth elements in the periodic system, which they justifiably termed "the rare-earth crisis" [8].

In the 35 years following the initial discovery, Mendeleev actually predicted a lot of new elements, which are summarized in Table 3 [1]. The predictions were scattered in the writings of the great Russian scientist as he continuously tried to improve them. Yet it is striking to see that more than half of his predictions were actually wrong: the corresponding elements were never found.

\section{Ether and the noble gases}

With today's knowledge, the two weirdest predictions of Mendeleev are found in Table 2 above helium: two elements that have smaller atomic masses than hydrogen [16, 34]. This story leads back to the discovery of noble gases, which occurred out of the blue within 5 years in the last decade of the 19th century in the laboratory of Sir William Ramsay (1852-1916). First came the obvious one: argon [35], which forms $1 \%$ of air. Mendeleev must have felt that the validity of the periodic law itself might be questioned by the existence of this new element [1]. First, argon did not have any place in his periodic system; it did not resemble any of the known elements. Second, its atomic mass was almost identical to that of calcium. Despite the clear spectroscopic evidence, Mendeleev first believed argon to be a triatomic form of nitrogen, which would have given 42 as the molecular mass and the inertness would have also not been unlike that of
Table 3 Mendeleev's predicted elements and the actual ones found later [1]

\begin{tabular}{|c|c|c|c|}
\hline Predicted element & $\begin{array}{l}\text { Predicted } \\
\text { atomic mass }\end{array}$ & $\begin{array}{l}\text { Actual element (year } \\
\text { of discovery) }\end{array}$ & $\begin{array}{l}\text { Actual } \\
\text { atomic } \\
\text { mass }\end{array}$ \\
\hline Newtonium, ether & 0.17 & - & \\
\hline Coronium & 0.4 & - & \\
\hline Un-named & 2 & - & \\
\hline Un-named & 8 & - & \\
\hline Un-named & 20 & - & \\
\hline Un-named & 22 & - & \\
\hline Un-named & 36 & - & \\
\hline Eka-boron & 44 & Scandium (1879) & 44.96 \\
\hline Eka-cerium & 54 & - & \\
\hline Eka-aluminum & 68 & Gallium (1875) & 69.72 \\
\hline Eka-silicon & 72 & Germanium (1887) & 72.61 \\
\hline Eka-manganese & 100 & Technetium (1937) & 98 \\
\hline Eka-molybdenum & 140 & - & \\
\hline Eka-niobium & 146 & - & \\
\hline Eka-cadmium & 155 & - & \\
\hline Eka-iodine & 170 & - & \\
\hline Eka-cesium & 175 & - & \\
\hline $\begin{array}{l}\text { Unnamed inert gas } \\
\text { (eka-xenon) }\end{array}$ & $137-180$ & - & \\
\hline Tri-manganese & 190 & Rhenium (1925) & 186.2 \\
\hline Dvi-tellurium & 212 & Polonium (1898) & (209) \\
\hline Un-named & & Astatine (1940) & (210) \\
\hline Dvi-cesium & 220 & Francium (1939) & (223) \\
\hline Un-named & & Actinium & $(227)$ \\
\hline Eka-tantalum & 235 & Protactinium (1913) & 231.0 \\
\hline
\end{tabular}

diatomic $\mathrm{N}_{2}$. In addition, $\mathrm{O}_{2}$ and $\mathrm{O}_{3}$ were both known at that time, so the analogy of a neighboring element was also a valid point. Mendeleev had to revise his opinion when further inert gas discoveries followed, but he was probably quite happy to do so. A discovery that was originally potentially lethal to his idea of the periodic law became very strong evidence supporting the correctness of his system. There was a place for an extra column in the periodic table between the halogens and the alkali metals, and helium, neon, krypton and xenon turned out to have atomic masses that matched exactly the values expected based on the placement of the new group. Argon was still an outlier in this sense. Mendeleev's dislike of this fact is obvious from Table 2, where he assigned the atomic mass 38 to Ar.

The periodic table shown in Table 2 was published in a 50-page article titled "An Attempt towards the Chemical Conception of the Ether" [33]. Ether here does not mean what is usually called ether today (the compound diethyl ether), but it is the physical abstraction of the medium that lets gravity and electromagnetic forces spread in space. In the very beginning of the 20th century, ether was thought 
to be an actual material that was difficult to detect in conventional ways: its only easily noticeable property was the interactions for which it provided the medium. It is notable that the existence of ether was accepted by a significant number of scientists even in the very early 1900s, despite the fact that the Michelson-Morley experiment [36], which is now understood to disprove the concept, was carried out and published in 1887. In this experiment, the speed of light was measured by the same method in April and July. The velocity vector of Earth on its orbit relative to the putative ether changed by about $90^{\circ}$ in this time interval, but the observations showed no difference in the speed of light at all.

In the mentioned long article [33], Mendeleev attempted to classify ether as a noble gas. This was a very logical thought in several ways [37]. First, noble gases are chemically inert and therefore difficult to detect. Argon is present in air at $1 \%$, yet it escaped scientific notice for a long time. So it did not seem inconceivable that other unreactive elements might still exist in nature. Second, there is an increase in the number of elements as we go down in Table 2. It was not far off to think that there are some earlier rows with even fewer spots. Series 1 had two elements in this prediction (hydrogen being the one with higher atomic mass) and a series 0 was introduced with a single element.

Mendeleev had at least one more serious, but apparently highly personal reason for introducing these two lighter-than-hydrogen predictions. At that time, many scientists accepted a theory called Prout's hypothesis [38-40], named after the English physician William Prout (1785-1850). This theory postulated that every element is eventually built up of the lightest one, hydrogen [38]. It is actually not far away from today's scientific views, as in our current understanding, most of the mass of the atoms is in the two nucleons, proton and neutron, both of which have almost the same mass as a hydrogen atom. From Prout's hypothesis, it clearly followed that no element can be lighter than hydrogen and it also seemed natural that atomic masses are very close to integers if they are calculated relative to hydrogen. Mendeleev was ardently opposed to Prout's hypothesis [1]. He was aware of the fact that atomic weights are not always whole number multiples of the atomic weight of hydrogen. Even in Table 1, the atomic masses shown with beryllium, aluminum and chlorine attest to this fact. As already mentioned, he actually revised the atomic mass of beryllium from an integer to a fractional number. His opposition to Prout's hypothesis was manifested by the fact that he insisted on the predictions of elements $x$ and $y$, which he called newtonium and coronium.

Similarly to other explicit element predictions, Mendeleev tried to estimate atomic masses for elements $x$ and $y$.
As these preceded all known elements, he could not rely on interpolation here; he had to use the much more dangerous practice of extrapolation. Unfortunately, the exact procedure is not described [33]. On the atomic mass of element $y$ (coronium), it says:

As the atomic weight of chlorine is 35.45 and that of fluorine is 19.0 , the ratio $\mathrm{Cl}: \mathrm{F}=35.4: 19.0=1.86$; so we also find:

Group VII ... Cl:F $=1.86$

$\mathrm{VI} \ldots \mathrm{S}: \mathrm{O}=2.00$

$\mathrm{V} \ldots \mathrm{P}: \mathrm{N}=2.21$

IV ... Si:C $=2.37$

III ... Al:B $=2.45$

II ... Mg:Be $=2.67$

I ... Na: $\mathrm{Li}=3.28$

$0 \ldots \mathrm{Ne}: \mathrm{He}=4.98$

This proves that the ratio in the given series distinctly and progressively increases in passing from higher to the lower groups; and, moreover, that it varies most rapidly between the first and zero groups. It follows therefore that the ratio He: $y$ will be considerably greater than the ratio $\mathrm{Li}: \mathrm{H}$ which is 6.97 , so that the ratio He: $y$ will be at least 10 and probably even greater. Hence, the atomic weight of $y$ will be not greater than $4.0 / 10=0.4$ and probably less.

On the atomic mass of element $x$, the following is written [33]:

Although it was possible to approximately determine the atomic weight of the element $y$ on the basis of that of helium, this cannot be repeated for the element $x$, because it lies at the frontier or limit, about the zero point of the atomic weights. Moreover, the analogues of helium cannot serve as a basis owning to the uncertainty of their numerical data. However, if the ratio of the atomic weights be $\mathrm{Xe}: \mathrm{Kr}=1.56: 1 ; \mathrm{Kr}: \mathrm{Ar}=2.15: 1$; and $\mathrm{Ar}: \mathrm{He}=9.5: 1$, we find that $\mathrm{He}: x=23.6: 1$, or if $\mathrm{He}=4.0$, that the atomic weight of $x=0.17$. This must be considered the maximum possible value. Most probably the atomic weight of $x$ is far less...

Both these descriptions tell the reader the raw data on which the prediction is based, but the mathematical algorithm is left in the dark and can only be guessed. In the next section, an attempt will be made to retro-engineer Mendeleev's thinking, so a way of thought will be sought that leads to the known final results. 
For element $y$, it is relatively easy to notice that the ratio of the first few atomic mass ratios $(6.97,4.98,3.28,2.67)$ is close to constant at 1.4 , so assuming a geometric series will probably be productive. This can easily be visualized graphically: the logarithms of the atomic mass ratios must be plotted with an equidistant scale on the $x$ axis. This is shown in Fig. 1. The intercept of a straight line is 9.5, so this could have been easily picked up by Mendeleev and interpreted as a value of at least 10 .

Finding the logic behind the estimate for element $x$ based on this text is even less straightforward. There are only four points here for atomic mass ratios, and these already include the one Mendeleev determined by extrapolation. Figure 2 shows a graph in which the ratios are given with an equidistant scaling on the $x$ axis. It can be noticed that the four points fit perfectly to a parabola (second order polynomial), which is a three-parameter curve, so the perfect fit is most probably not accidental: this is how Mendeleev obtained the extrapolated value. The use of the parabola is not simply guesswork here: the text quoted above was translated into English from Russian, but there is a German translation of the same text as well, which is slightly different and gives an important clue [41, 42]:

Wenn wir aber beachten, dass das Verhältniss der Atomgewichte $\mathrm{Xe}: \mathrm{Kr}=1,56: 1, \mathrm{Kr}: \mathrm{Ar}=2,15: 1$ and Ar:He 9,50:1 ist, so finden wir aus einer Parabel zweiter Ordnung das Verhältniss von He: $x=23,6: 1$, d. h. wenn $\mathrm{He}=4$, die Grösse des Atomgewichtes von $x=0,17$, was als die höchste mögliche Zahl angesehen werden muss.

(Translation: However, if the ratio of the atomic weights be $\mathrm{Xe}: \mathrm{Kr}=1.56: 1 ; \mathrm{Kr}: \mathrm{Ar}=2.15: 1$; and $\mathrm{Ar}: \mathrm{He}=9.5: 1$, with the use of a second order parabola we find that $\mathrm{He}: x=23.6: 1$, or if $\mathrm{He}=4.0$, that the

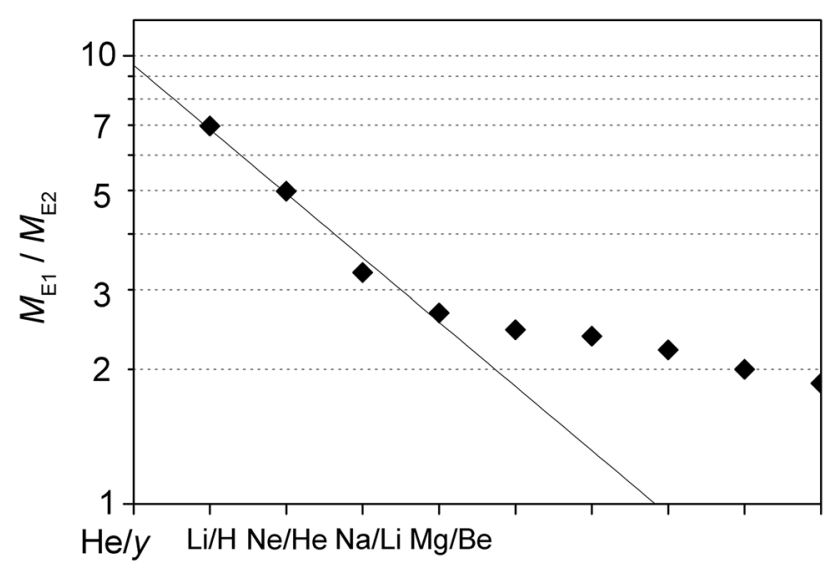

Fig. 1 A graphical method for estimating the atomic mass of element y

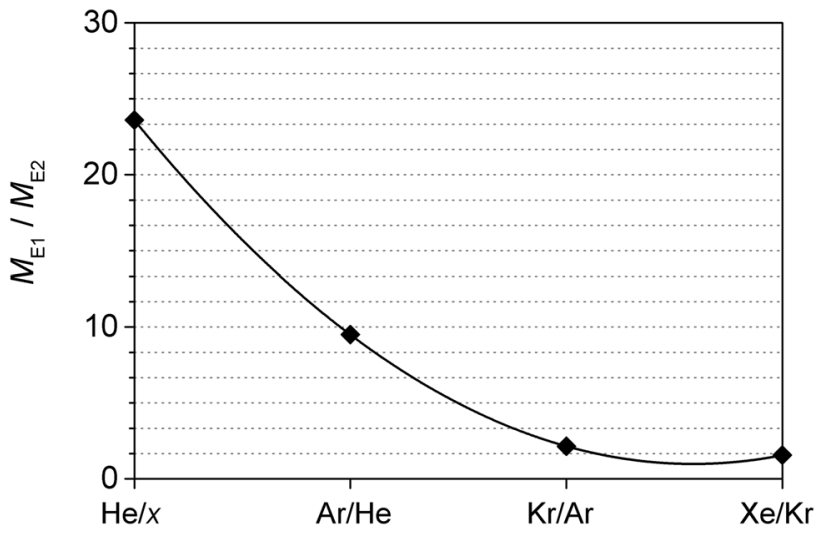

Fig. 2 A graphical demonstration of the method used for estimating the atomic mass of element $x$

atomic weight of $x=0.17$, which must be considered the maximum possible value.)

It is unlikely that Mendeleev had the means to fit a parabola to three points in a figure graphically. Even more conspicuous is the fact that the fitted parabola has a minimum between points three and four, which is within the studied range. Extrapolation of monotonic data with a non-monotonic curve is visually highly unappealing and would probably not be considered good science in general. One possible solution to these riddles is presented in Table 4. In essence, this involves parabolic extrapolation in a tabular form. The numbers in the upmost row are the atomic mass ratios, one of which is unknown. Based on the known numbers, their differences are calculated in the lower cells of the table in a way that the value in a cell is always obtained by subtracting the number on the upper right from the number on the upper left. In this way, the numbers given in normal letters in the table can all be obtained. Then, it is assumed that the number in the bottom cell (shaded background) is 0 , and the table is completed calculating in a reverse way (boldface numbers). This procedure gives exactly 23.6 in the upper left cell. What is more, the non-monotonic nature of the extrapolating function also stays hidden in the tabular method.

Table 4 A possible tabular method to estimate the atomic mass of element $x$

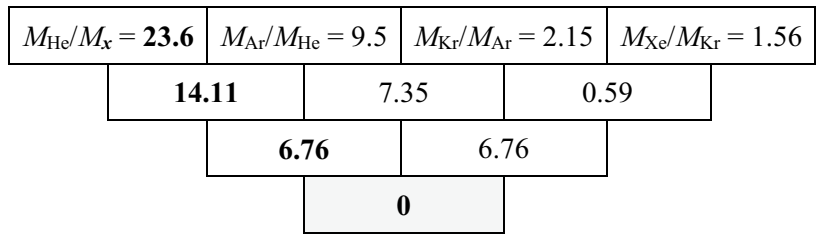




\section{Disproof and verification in the early 20th century}

Mendeleev's idea of the chemical conception of ether was a short-lived one. In 1905, Albert Einstein (1879-1955) published one of his most famous papers on the theory of special relativity, which did not have any room for ether; it showed a convincingly logical way of physical thinking without this concept [43]. This theory did not mean that no lower analogs of the noble gases could exist, it simply removed the necessity arising from physics. Neither did physicists drop the idea of ether suddenly: in 1922, Einstein himself noted that the relativity theory itself could be thought of as a sort of ether, as it implied that the empty space without any objects still had its own physical structure [44]. Even as late as 1951, one of the most significant physicists of the 20th century, Paul Dirac (1902-1984) wrote an article titled "Is there an Aether?" [45].

The problem of the placement of the rare earth metals was also resolved in 1905 when Swiss chemist Alfred Werner (1866-1919) published a notable article [46]. In effect, he gave up the idea of trying to place them in the conventional 18 groups but created 15 new groups instead, 14 of which are customarily shown today as a separate part under the main table and the 15th is inserted below yttrium. In 1905, most of these groups contained a single element. Thorium was correctly placed below cerium, but uranium was shown below europium, which turned out to be a mistake; its correct position is below neodymium. Werner was awarded the Nobel Prize in Chemistry in 1913, but not for his achievements on the periodic table.

The year 1913, 6 years after the death of Mendeleev, brought some sort of a closure for developing the scientific background of the system of the elements. The English physicist Henry Gwyn Jeffreys Moseley (1887-1915) discovered a striking regularity in the X-ray fluorescence spectra of the elements $[47,48]$. In such spectra, the most visually prominent or intense line is called the $\mathrm{K}_{\alpha}$ line. Moseley found that the frequency of $\mathrm{K}_{\alpha}$ lines for all elements can be given with a very simple formula, in which the identity of the element is represented by only a single integer number. This integer actually mostly coincided with the position of the element in the periodic table (i.e. hydrogen had number one, helium number two, carbon number six, sodium number 11, and so on). So he discovered the concept of atomic number and also showed that the order of elements in Mendeleev's periodic table follows the order of atomic numbers rather than that of atomic masses. The formula is called Moseley's law today and had immense predictive power for the discovery of unknown elements. It immediately resolved the issue of anomalous atomic masses $(\mathrm{Ar}-\mathrm{K}$, Te-I) and also made it obvious that most of Mendeleev's element predictions were actually wrong.
In the same year, the Danish physicist Niels Henrik David Bohr (1885-1962) published four papers on the electron structure of atoms [49-52]. His theory made it clear that the chemical similarities of the elements are caused by the analogous valence shell electron structures within one group. It is somewhat ironic that the discoveries of Moseley and Bohr made most of Mendeleev's element predictions untenable, but also illuminated the hitherto unknown scientific logic behind the periodic table and removed all doubts as to its role as the natural order in the kingdom of chemical elements.

\section{Conclusion}

The history of science shows that major conclusions are almost never established in a straightforward way, and momentous new ideas are seldom reported to audiences in the manner they were conceived. This is nicely illustrated by the history of the first half century of the periodic table, between Mendeleev's initial publications to the results of 1913. One of the strongest facts quoted in support of Mendeleev's ingenuity today are the element predictions he made. Strictly speaking, his success rate at the predictions was worse than $50 \%$, which is not always seen as outstanding in science. However, it is arguable that some groups of erroneous predictions have the same origin and it may not be entirely fair to view them as separate from each other. Whilst most of the successful predictions were verified within the lifetime of Mendeleev, the mistakes only became apparent at a time when the evidence supporting the validity of the periodic law and the periodic table as the natural system of elements was already overwhelming.

Acknowledgements Open access funding provided by University of Pécs (PTE).

Open Access This article is distributed under the terms of the Creative Commons Attribution 4.0 International License (http://creativeco mmons.org/licenses/by/4.0/), which permits unrestricted use, distribution, and reproduction in any medium, provided you give appropriate credit to the original author(s) and the source, provide a link to the Creative Commons license, and indicate if changes were made.

\section{References}

1. Scerri ER (2006) The periodic table: its story and its significance. Oxford University Press, Oxford

2. Trifonov DN (1966) Mendeleev and the rare earths in problems in the study of rare earths. Israel program for scientific translations, Jerusalem

3. van Sprosen JW (1969) The periodic system of chemical elements: a history of the first hundred years. Elsevier, Amsterdam

4. Scerri ER, Worrall J (2001) Prediction and the periodic table. Stud Hist Phil Sci 32:407-452

5. Brooks NM (2002) Developing the periodic law: Mendeleev's work during 1869-1871. Found Chem 4:127-147

6. Brush SG (2007) Predictivism and the periodic table. Stud Hist Philos Sci 38:256-259 
7. Schindler S (2014) Novelty, coherence, and Mendeleev's periodic table. Stud Hist Philos Sci 45:62-69

8. Thyssen P, Binnemans K (2015) Mendeleev and the rare-earth crisis. In: Scerri E, McIntyre L (eds) Philosophy of chemistry. Springer, Dordrecht

9. Hodder P (2018) The periodic table: revelation by quest rather than by revolution. Found Chem 20:99-110

10. Stewart PJ (2019) Mendeleev's predictions: success and failure. Found Chem 21:3-9

11. Cheisson T, Schelter EJ (2019) Rare earth elements: Mendeleev's bane, modern marvels. Science 363:489-493

12. Wray KB (2019) What to make of Mendeleev's predictions? Found Chem 21:139-143

13. Kirchhoff G, Bunsen RWE (1860) Chemische analyse durch Spectralbeobachtungen (translation: Chemical analysis by spectral observations). Ann Phys 186:161-181

14. Kirchhoff G, Bunsen RWE (1860) Chemical analysis by spectrumobservations. Philos Mag Ser 4(20):88-109

15. https://en.wikipedia.org/wiki/Mendeleev\%27s_predicted_eleme nts. Accessed 23 July 2019

16. Kovács L, Csupor D, Lente G, Gunda T (2014) 100 Chemical myths-misconceptions, misunderstandings, explanations. Springer, Cham

17. Kaji M (2002) D. I. Mendeleev's concept of chemical elements and the principles of chemistry. Bull Hist Chem 27:4-16

18. Mendeleev DI (1869) Соотношеніе свойствъ сь атомным въсомъ элементовъ (Modern Russian orthography: Соотношение свойств с атомным весом элементов; BGN/ PCGN romanization: sootnoshenie svoystv s atomnym vesom elementov; translation: The correlation of the properties and atomic weights of the elements). Zh Russ Khim Obshch 1:60-77

19. Mendeleev DI (1869) Versuch eines Systems der Elemente nach ihren Atomgewichten und chemischen Funktionen (translation: An attempted system of the elements based on their atomic weights and chemical analogies). J Prakt Chem 106:251

20. Mendeleev DI (1869) Über die Beziehungen der Eigenschaften zu den Atomgewichten der Elemente (translation: On the correlation between the properties of the elements and their atomic weights). Z f Chem 5:405-406

21. Andriiko AA, Lunk HJ (2018) The short form of Mendeleev's periodic table of chemical elements: toolbox for learning the basics of inorganic chemistry. A contribution to celebrate 150 years of the periodic table in 2019. ChemTexts 4:4

22. Lothar Meyer JL (1864) Die modernen Theorien der Chemie und ihre Bedeutung für die chemische Statistik (translation: The modern theories of chemistry and their importance for chemical statistics). Maruschke and Berendt, Breslau

23. Mendeleev DI (1889) The Periodic law of the chemical elements. J Chem Soc Trans 55:634-656

24. de Boisbaudran L (1875) Caractères chimiques et spectroscopiques d'un nouveau métal, le gallium, découvert dans une blende de la mine de Pierrefitte, vallée d'Argelès (Pyrénées). (translation: Chemical and spectroscopic properties of a new metal, gallium, discovered in a blende from Pierrefitte mine, valley of Argelès, Pyrenees). Compt Rend 81:493-495

25. Nilson LF (1879) Sur l'ytterbine, terre nouvelle de M. Marignac (translation: On ytterbium, a new earth metal of M. Marignac). Compt Rend 88:642-647

26. Winkler C (1886) Germanium, Ge, ein neues, nichtmetallisches Element (English: Germanium, Ge, a new nonmetal element). Ber Deutsch Chem Ges 19:210-211

27. Perrier C, Segre E (1937) Some chemical properties of element 43. J Chem Phys 5:712-716

28. Perrier C, Segre E (1937) Radioactive isotopes of element 43. Nature 140:193-194
29. Mosander CG (1843) On the new metals, lanthanium and didymium, which are associated with cerium; and on erbium and terbium, new metals associated with yttria. Philos Mag Ser 3(23):241-254

30. Moissan H (1886) Action d'un courant électrique sur l'acide fluorhydrique anhydre (translation: Effect of an electric current on anhydrous hydrofluoric acid). Compt Rend 102:1543-1544

31. Mosander CG (1842) Ein neues Metall, Didym, betreffend (translation: Concerning a new metal, Didymium). Pogg Ann Phys 56:503-505

32. Auer von Welsbach C (1885) Die Zerlegung des Didyms in seine Elemente (translation: The decomposition of Didymium into its elements). Monat Chem 6:477-491

33. Mendeleev DI (1904) An attempt towards a chemical conception of the ether. Longmans Green Co, London

34. van Sprosen JW (1981) Mendeleev as a speculator. J Chem Educ 58:790-791

35. Strutt RJ, Ramsay W (1895) Argon, a new constituent of the atmosphere. Proc R Soc 57:265-287

36. Michelson AA, Morley EW (1887) On the relative motion of the Earth and the luminiferous ether. Am J Sci 34:333-345

37. Bensaude-Vincent B (1982) L'Éther, Élement Chimique: Un Essai Malheureux De Mendéléev? (translation: ether, the chemical element: an essay that deheroizes Mendeleev?). Brit J Hist Sci 15:183-188

38. Prout W (1815) On the relation between the specific gravities of bodies in their gaseous state and the weights of their atoms. Ann Philos 6:321-330

39. Brock WH (1963) Prout's chemical bridgewater treatise. J Chem Educ 40:652-655

40. Brock WH (1985) From protyle to proton William Prout and the nature of matter, 1785-1985. Adam Hilger Ltd, Bristol and Boston

41. Mendelejew DI (1903) Versuch einer chemischen Auffassung des Weltäthers (translation: attempt at the chemical conception of ether). Prometh illus Wochenschr über die Fortschr Gewerbe Ind und Wiss 15:129-134

42. Mendelejew DI (1904) Versuch einer chemischen Auffassung des Weltäthers (translation: attempt at the chemical conception of ether). Naturwiss Rundschau 19:289-291 (the text slightly deviates from the text in [41])

43. Einstein A (1905) Zur Elektrodynamik bewegter Körper (translation: electrodynamics of moving bodies). Ann Phys 322:891-921

44. Einstein A (1922) Ether and the theory of relativity in sidelights on relativity. Methuen, London

45. Dirac $P(1951)$ Is there an aether? Nature 168:906-907

46. Werner A (1905) Beitrag zum Ausbau des periodischen Systems (translation: Contribution to the structure of the periodic system). Ber Deutsch Chem Ges 38:914-921 (now in: Eur J Inorg Chem 38:914-921)

47. Moseley HGJ (1913) The high-frequency spectra of the elements. Philos Mag Ser 6(26):1024-1034

48. Moseley HGJ (1914) The high-frequency spectra of the elements II. Philos Mag Ser 6(27):703-714

49. Bohr NHD (1913) On the constitution of atoms and molecules. Philos Mag Ser 6(26):1-25

50. Bohr NHD (1913) On the constitution of atoms and molecules. Part II. Systems containing only a single nucleus. Philos Mag Ser 6(26):476-502

51. Bohr NHD (1913) On the constitution of atoms and molecules. Part III. Systems containing several nuclei. Philos Mag Ser 6(26):857-875

52. Bohr NHD (1913) The spectra of helium and hydrogen. Nature 92:231-232

Publisher's Note Springer Nature remains neutral with regard to jurisdictional claims in published maps and institutional affiliations. 